\section{Re: Does Prescription Opioid Misuse Affect the Level of Health Care Satisfaction Endorsed by Patients on Opioid Therapy?}

To the Editor: I commend Dr. Jerant and colleagues ${ }^{1}$ on their article entitled "Satisfaction with Health Care among Prescription Opioid Recipients." In the said article, the authors rightfully noted that 2 potential explanations for the findings could be the long duration of opioid use with $\geq 6$ opioid prescriptions and the pharmacological euphoric effects of opioids. Moreover, insofar as trust indicates patients' satisfaction, ${ }^{2,3}$ the authors' findings seem to be supported by Sherman and colleagues, ${ }^{4}$ who also noted that patients on chronic opioid therapy trust their health care providers, whereas patients who were worried that their prescription opioids would be reduced in an opioid reduction initiative were less likely to trust their health care providers. However, there is an issue regarding confounders that I would like to be clarified.

The authors noted that the full regression model controlled for physical and mental health status, using the 12-item Short-Form Health Survey (SF-12) as a proxy. However, the SF-12 does not account for opioid misuse and substance use. Substance use and a high daily dose of prescription opioids are predictors of opioid misuse. ${ }^{5}$ Because opioid misuse (not conforming to the prescribed pattern of opioid use, irrespective of one's adverse effects status $^{6}$ ) is highly prevalent among patients with legitimate opioid prescriptions (occurring in $21 \%$ to $29 \%$ of these patients ${ }^{6}$ ), and illicit drug use coupled with alcohol abuse has been identified to predict opioid misuse among chronic pain patients, ${ }^{7}$ it might be educative to include substance use as a covariate in the regression model. This is because doing so might help in answering such relevant questions as, are prescription opioid misusers more or less likely to endorse high or low patient satisfaction in health care? In addition, physicians' prescription serve as a major source of diversion ${ }^{8}$ and misuse, ${ }^{9}$ is it possible that patients who would like to divert (share/sell prescription opioids to others ${ }^{10}$ ) their prescription opioids may endorse higher satisfaction, with an increased number of prescriptions by their health care providers? In this regard, it may be interesting and educative to observe the effect of both opioid misuse and substance use adjusted for in the full regression model. However, it is entirely possible that these variables were not available in the dataset used for the analysis.
Ayodeji Otufowora, MD, MPH, CPH Department of Epidemiology, College of Public Health and Health Professions and College of Medicine, University of Florida, Gainesville deji.otufowora@ufl.edu

To see this article online, please go to: http://jabfm.org/content/ 33/3/484.full.

\section{References}

1. Jerant A, Agnoli A, Franks P. Satisfaction with health care among prescription opioid recipients. J Am Board Fam Med 2020;33:34-41.

2. Dyer TA, Owens J, Robinson PG. The acceptability of healthcare: from satisfaction to trust. Community Dent Health 2016;33:242-51.

3. Birkhäuer J, Gaab J, Kossowsky J, et al. Trust in the health care professional and health outcome: a meta-analysis. PLoS One 2017;12:e170988.

4. Sherman KJ, Walker RL, Saunders K, et al. Doctorpatient trust among chronic pain patients on chronic opioid therapy after opioid risk reduction initiatives: a survey. J Am Board Fam Med 2018;31:578-87.

5. Sullivan MD, Edlund MJ, Fan M-Y, Devries A, Brennan Braden J, Martin BC. Risks for possible and probable opioid misuse among recipients of chronic opioid therapy in commercial and Medicaid insurance plans: the TROUP Study. Pain 2010;150:332-9.

6. Vowles KE, McEntee ML, Julnes PS, Frohe T, Ney JP, van der Goes DN. Rates of opioid misuse, abuse, and addiction in chronic pain: a systematic review and data synthesis. Pain 2015;156:569-76.

7. Turk DC, Swanson KS, Gatchel RJ. Predicting opioid misuse by chronic pain patients: a systematic review and literature synthesis. Clin J Pain 2008;24:497-508.

8. Shei A, Rice JB, Kirson NY, et al. Sources of prescription opioids among diagnosed opioid abusers. Curr Med Res Opin 2015;31:779-84.

9. Holliday S, Hayes C, Dunlop A. Opioid use in chronic non-cancer pain-part 1: known knowns and known unknowns. Aust Fam Physician 2013;42:98-102.

10. Larance B, Degenhardt L, Lintzeris N, Winstock A, Mattick R. Definitions related to the use of pharmaceutical opioids: extramedical use, diversion, non-adherence and aberrant medication-related behaviours. Drug Alcohol Rev 2011;30:236-45.

doi: 10.3122/jabfm.2020.03.200022 